\title{
Immunology in clinic review series; focus on autoinflammatory diseases: role of inflammasomes in autoinflammatory syndromes
}

OTHER THEMES PUBLISHED IN THIS IMMUNOLOGY IN THE CLINIC REVIEW SERIES

Allergy, Host Responses, Cancer, Type 1 diabetes and viruses, Metabolic diseases.

\author{
V. U. Ozkurede and L. Franchi \\ Department of Pathology and Comprehensive \\ Cancer Center, University of Michigan Medical \\ School, Ann Arbor, MI, USA
}

\author{
Accepted for publication 18 November 2011 \\ Correspondence: L. Franchi, Department of \\ Pathology, University of Michigan Medical \\ School, 4131 CCGC, 1500 E. Medical Center \\ Drive, Ann Arbor, MI 48109, USA. \\ E-mail: luigif@umich.edu
}

\begin{abstract}
Summary
Autoinflammatory syndromes are disorders characterized by the hyperactivation of the innate immune system in the absence of microbial infection or autoantibody production. Some autoinflammatory syndromes are associated with recurrent episodes of fever and systemic inflammation that are caused by dysregulated activation of inflammasomes, molecular platforms responsible for the activation of caspase- 1 and the production of interleukin (IL)- $1 \beta$. In this review we will discuss the role of IL- $1 \beta$ and the inflammasomes in host defence and how mutations of two genes, NLRP3 and PYRIN, leads to the autoinflammatory syndromes, cryopyrin-associated periodic syndromes (CAPS) and familial Mediterranean fever (FMF). Both CAPS and FMF are characterized by increased inflammasome activity and overproduction of IL-1 $\beta$ which is ultimately responsible for disease manifestations. Importantly, understanding the molecular mechanisms of these syndromes has led to effective treatment for these rare diseases with biological drugs that target IL-1 $\beta$-mediated signalling.
\end{abstract}

Keywords: IL-1 $\beta$, inflammasome, inflammation, innate immunity

\section{Introduction}

The immune system can be categorized broadly as innate and adaptive. Disorders of the immune system may be due to hyperactivation or impaired activation of either the innate or the adaptive immune systems. In the case of deficient activation of the immune system the resultant diseases are called immunodeficiencies, and are characterized phenotypically by recurrent episodes of infection. An exaggerated activation of the adaptive immune system results in the generation of self-reactive lymphocytes and high-titre autoantibodies that are typical features of autoimmune diseases. In contrast, disorders of the innate immune system with little or no involvement of $\mathrm{T}$ and $\mathrm{B}$ cells are called autoinflammatory syndromes and are characterized by recurrent episodes of fever and systemic inflammation in the absence of microbial infection [1]. For some of these diseases, the gene responsible for the exaggerated activation of the immune system has been identified, and the list of hereditary autoinflammatory syndromes is constantly growing due to the discovery of different genetic mutations that underlie these disorders. Here we will focus on those disorders in which the genetic mutation responsible for the disease that triggers an exaggerated production of interleukin (IL)-1 $\beta$ is due to dysregulation of inflammasomes, and we refer the reader to other excellent reviews for a more comprehensive classification of autoinflammatory syndromes [1-4].

\section{IL-1 $\beta$}

IL-1 $\beta$ is a powerful mediator of inflammatory responses [5]. Systemically, IL-1 $\beta$ induces fever and the hepatic acute phase response that includes $\mathrm{C}$-reactive protein and serum amyloid $\mathrm{A}$, and acts on the bone marrow to promote neutrophilia. At a local level, IL-1 $\beta$ induces expression of cell adhesion molecules such as intercellular adhesion molecule-1 (ICAM-1), vascular adhesion molecule-1 (VCAM-1), P-selectin and E-selectin [6,7], which promote neutrophil recruitment to inflamed tissues $[8,9]$. In addition, IL- $1 \beta$ acts directly on neutrophils and other leucocyte populations to regulate their activation and production of other mediators of inflammation such as tumour necrosis factor (TNF)- $\alpha$ and IL-6 [8]. These observations suggest that IL- $1 \beta$ has a role in host defence, and indeed there is compelling evidence that mice 
deficient in IL-1 $\beta$ are more susceptible than wild-type to infection with bacteria, viruses or fungi $[10,11]$. Based on the effect of injection of recombinant IL- $1 \beta$, the concentration of IL- $1 \beta$ that promotes host defence in humans has been estimated to be $\sim 1-10 \mathrm{ng} / \mathrm{kg}$. However, when produced for an excessive period of time, IL- $1 \beta$ causes tissue damage, bone resorption, collagen deposition and neovascularization. Moreover, IL-1 $\beta$ produced in large amounts promotes harmful systemic responses, including hypotension at concentrations higher than $30 \mathrm{ng} / \mathrm{kg}$ and haemodynamic shock at concentrations higher then $300 \mathrm{ng} / \mathrm{kg}$. This evidence suggests that the production of IL- $1 \beta$ must be tightly controlled to avoid detrimental effects or even death due to haemodynamic shock [8]. We will discuss first how the production of IL-1 $\beta$ is normally controlled in healthy individuals and then discuss the molecular mechanisms that are involved in the excessive production of IL-1 $\beta$ in selected autoinflammatory syndromes. It is worth mentioning that the symptoms common to all autoinflammatory syndromes, such as episodes of fever, increased concentration of acute phase proteins that can lead to amyloidosis and accumulation of neutrophils at involved sites, can be caused by IL-1 $\beta$ overproduction, which might explain the efficacy of biologicals that target IL- $1 \beta$ in the treatment of these disorders.

\section{Regulation of IL-1 $\beta$ production}

The production and action of IL-1 $\beta$ is regulated at different levels: induction of the immature cytokine pro-IL-1 $\beta$, maturation of pro-IL-1 $\beta$ into the biologically active cytokine IL- $1 \beta$, secretion of IL- $1 \beta$ and binding of IL- $1 \beta$ to IL- $1 R$ on target cells. In monocytes, macrophages and dendritic cells pro-IL- $1 \beta$ is expressed only at very low levels. Several cytokines, including TNF- $\alpha$, IL- $1 \alpha$ and IL- $1 \beta$, as well as stimulation of phagocytic cells with Toll-like receptor (TLR)ligands such as lipopolysaccharide (LPS), that signals via TLR-4, or NLR [nucleotide oligomerization domain (NOD)-like receptor]-ligands, such as muramyl dipeptide (MDP) that signals via NOD2, induce activation of the transcription nuclear factor $(\mathrm{NF})-\kappa \mathrm{B}$ and the up-regulation of pro-IL-1 $\beta$ [12-14]. Therefore, proinflammatory cytokines and stimulation of the innate immune system are necessary for the production of pro-IL-1 $\beta$. However, in the absence of a 'secondary stimulus', the maturation of pro-IL-1 $\beta$ is very inefficient. The maturation of pro-IL-1 $\beta$ is mediated by proteolytic processing into $17-\mathrm{kDa}$ mature IL- $1 \beta$ by the cysteine-protease caspase-1. Caspase- 1 itself is present in the cytosol as an inactive protein, pro-caspase- $1[15,16]$. The activation of caspase- 1 is mediated by its autoproteolytic cleavage. In the last decade, we and others have found that the 'secondary stimulus' that induces the production of IL-1 $\beta$ promotes the formation of a molecular platform, generically called inflammasome, which induce the oligomerization and activation of procaspase-1, and will be discussed in more detail later. Once activated, the inflamma- some induces the activation of caspase- 1 that mediates the maturation of IL-1 $\beta$ [16]. The next step is the secretion of IL- $1 \beta$ in the extracellular environment. IL- $1 \beta$ lacks the leader sequence found generally in secreted proteins, and several non-conventional routes of secretion have been proposed including exosome shedding [17], shedding of plasma membrane microvesicles [18] and lysosomal secretion [19], which might be amplified further by membrane permabilization secondary to necrosis. It is worth mentioning that caspase-1 activation, IL- $1 \beta$ processing and its secretion are highly associated processes [20]. Next, the secreted IL-1 $\beta$ binds to its receptor IL-1R, a process that is inhibited by its natural antagonist IL-1Ra (IL-1F3), a protein that is also secreted in response to many proinflammatory stimuli. IL-1Ra binds to the cell surface IL-1R with higher affinity than IL-1 $\beta$ and prevents IL-1 $\beta$ from signalling. Mice deficient in IL-1Ra develop arthritis [21] and arteritis [22], underscoring the importance of IL-1Ra in regulating the activity of IL-1 $\beta$. Strikingly, infants born with non-functional IL-1Ra develop a lethal inflammatory disorder, characterized by neutrophilladen pustular skin eruption, vasculitis and bone abnormalities in the absence of any detectable infection $[23,24]$. This autoinflammatory syndrome, called DIRA (deficiency in IL-1 receptor antagonist) is currently treated efficiently with a recombinant IL-1Ra, anakinra, that prevents all disease manifestations $[23,24]$.

\section{Inflammasomes}

Inflammasomes are molecular platforms responsible for the activation of caspase-1, a cysteine protease that mediates proteolytic processing and activation of the proinflammatory cytokines IL-1 $\beta$ and IL-18 $[15,25]$. The first evidence for the existence of the inflammasome was described originally in cell extracts of human acute monocytic (THP-1) cells incubated in a buffer containing low levels of $\mathrm{K}^{+}$[26]. Evidence accumulated in the last 5 years demonstrated that different physiological stimuli engage different inflammasomes to induce the activation of caspase-1, and these platforms have been named the NLRP1-inflammasome, the NLRP3-inflammasome, the NLRC4-inflammasome and the absent in melanoma 2 (AIM2) inflammasome [15,25,27]. NLRP1, NLRP3 and NLRC4 belong to the NLR family, a family of PRRs that sense pathogen-associated molecular patterns (PAMPs) or endogenous signals of stress in the cytosol. In agreement with their role in sensing cytosolic PAMPs, the mouse Nlrp1b inflammasome is activated anthrax lethal toxin from Bacillus anthracis, whereas the human NLRP1 is activated by muramyl dipeptide (MDP) [28]. The NLRC4-inflammasome is activated by cytosolic flagellin from Salmonella typhimurium [29,30], Pseudomonas aeruginosa [31] and Legionella pneumophila [32,33]. Interestingly, the activation of the NLRC4-inflammasome, at least in certain experimental settings, is assisted by neuronal apoptosis inhibitor proteins (NAIPs) [34]. The 
NLRC4-inflammasome is also activated by a flagellinindependent pathway in macrophages infected with Shigella flexneri [35], and this pathway may be dependent on MxiI, a basal body rod component of the T3SS apparatus [36]. The NLRP3 inflammasome is the most complex and most studied inflammasome and will be discussed separately and in more detail later. AIM2 is a member of the HIN200 protein family and is a cytosolic receptor for double-strand DNA. AIM2 is important for the activation of caspase-1 in response to vaccinia virus, mouse cytomegalovirus (mCMV) and the bacterial pathogen Francisella tularensis [37,38]. It is worth mentioning that bacteria can engage multiple inflammasomes. For example, there is evidence that Listeria monocytogenes can activate the NLRC4-inflammasome, the NLRP3-inflammasome and the AIM2 inflammasome [39-44]. There is also evidence that inflammasomeindependent pathways can induce maturation of IL-1 $\beta$ $[45,46]$.

\section{NLRP3 inflammasome}

The NLRP3 inflammasome is the most studied, and most controversial, inflammasome. The NLRP3 inflammasome is unique in that it is the only inflammasome described so far that can be activated by non-microbial stimuli $[15,47]$. The NLRP3 inflammasome can also be activated by microbes [48].

Activation of the NLRP3-inflammasome requires the combination of two separate signals. 'Signal 1' is necessary to prime macrophages and dendritic cells to a subsequent 'signal 2', that can be considered the true activator of the inflammasome [15,25]. The existence of a 'signal 1' was suggested initially by the observation that adenosine triphosphate (ATP), an activator of the NLRP3-inflammasome, can activate caspase- 1 efficiently only in cells pretreated with LPS [49]. We and others found later that in the absence of stimulation with PAMPs several activators of the NLRP3 inflammasome, in addition to ATP, fail to induce caspase-1 activation [50,51]. It was found that PAMPs prime macrophages through a transcriptional event induced by TLR- or NOD-like receptor (NLR)-signalling pathways and mediated via the transcription factor NF-kB [50,51]. Thus, in the case of the NLRP3 inflammasome, $\mathrm{NF}-\kappa \mathrm{B}$ activation is not only important for the production of pro-IL-1 $\beta$, but also for activation of the inflammasome. Importantly, Hornung and colleagues found that TLRsignalling induces up-regulation of NLRP3 itself and that in cells over-expressing NLRP3 priming is not necessary for the activation of caspase- 1 induced by ATP [50]. These data suggest that one important feature of priming is the up-regulation of NLRP3 itself. It is worth mentioning that in human monocytes, stimulation with PAMPs induces the production of IL-1 $\beta$ in the absence of exogenous stimulation with ATP [52]. Recent studies showed that PAMP stimulation of freshly isolated monocytes promotes the release of endogenous ATP that act in a autocrine fashion on the purinerig receptor P2X7 to promote caspase- 1 activation and IL-1 $\beta$ production [53]. These data indicate that the activation of the NLRP3 inflammasomes in human monocytes, mouse macrophages and dendritic cells require two signals.

If priming is necessary for the activation of the NLRP3 inflammasome how can the NLRP3 inflammasome be activated in a sterile environment, where PAMPs are not present? We found that endogenous cytokines, such as TNF- $\alpha$, IL- $1 \alpha$ and IL-1 $\beta$, can prime macrophages and dendritic cells efficiently for the activation of the NLRP3-inflammasome induced by danger signals and particulate matter [51]. Thus, endogenous cytokines are sufficient to provide 'signal 1' for the activation of the NLRP3-inflammasome. 'Signal 2' for NLRP3 activation can be provided by microbial and nonmicrobial stimuli. Examples of signal 2 of microbial origin include pore-forming toxins [54,55] and microbial RNA species [56]. Consistently, the NLRP3 inflammasome has been involved in the activation of caspase- 1 induced by bacteria [48], viruses [57] and fungi [58]. Examples of NLRP3 activators generated in sterile environments are the danger signal ATP [59], monosodium crystals [60], calcium pyrophosphate dehydrate crystals [60], cholesterol crystals [61] and oligomers of islet amyloid polypeptide (IAPP) [62]. Interestingly, those activators of the NLRP3-inflammasome have been involved in the pathogenesis of diseases such as gout, pseudogout, atherosclerosis and type II diabetes that are diseases that have a significant inflammatory component. One important question, and the reason of much controversy, is whether stimuli of such different nature converge on a common pathway to activate NLRP3. Several theories have been proposed. The first theory is that NLRP3 senses the concentration of cytosolic $\mathrm{K}^{+}$. Stimuli such as the danger signal ATP that engage the purinergic receptor $\mathrm{P} 2 \mathrm{X} 7$ and bacterial pore-forming toxins induce $\mathrm{K}^{+}$efflux, thus reducing the cytosolic $\mathrm{K}^{+}$concentration $[39,41]$. In agreement with the role of $\mathrm{K}^{+}$in activation of the NLRP3inflammasome, extracellular medium rich in $\mathrm{K}^{+}$that prevent the decrease of cytosolic $\mathrm{K}^{+}$concentration block the activation of the NLRP3-inflammasome. The second mechanism proposes that particulate matter induces damage of the lysosome, which is followed by the release of lysosomal molecules, such as cathepsin B, which will be responsible for the activation of NLRP3 [63]. In this respect it is worth mentioning that serine-protease inhibitors can efficiently block the activation of the NLRP3-inflammasome [64]. A third mechanism proposes that reactive oxygen species (ROS) generated by the mitochondria activate TXNIP which, in turn, binds to and activate the NLRP3-inflammasome [65]. It must be noted, however, that the role of TXNIP is controversial in that cells deficient in TXNIP respond normally to stimuli that activate the NLRP3-inflammasome [62]. Moreover, there is evidence that ROS can inhibit caspase- 1 activity by glutathionylation of the redox-sensitive cysteine residues 
Cys397 and Cys362 [66]. Furthermore, recent evidence indicates that agents commonly used to block ROS generation actually prevent the up-regulation of NLRP3 [67] and proIL-1 $\beta$ [68], indicating that they act mainly at the level of signal 1. Consistently, inhibitors of ROS do not block the activation of caspase-1 in cells that express NLRP3 [67].

\section{Cryopyrin-associated periodic syndromes (CAPS)}

Familial cold autoinflammatory syndrome (FCAS), MuckleWells syndrome (MWS) and neonatal onset multi-system inflammatory disease (NOMID) [also called chronic infantile neurologic cutaneous articular syndrome (CINCA)] are different manifestations of one disease, in that they are all caused by autosomal-dominant mutations in NLRP3. Therefore, FCAS, MWS and NOMID are now collectively called cryopyrin-associated periodic syndromes (CAPS) [69,70]. FCAS represents the less severe manifestation of CAPS and is characterized by cold-induced fever and urticaria-like rashes. MWS is more severe, and patients have also sensorineural hearing loss and arthritis. NOMID is the most severe form of CAPS, and patients have epiphyseal overgrowth of the long bones and chronic aseptic meningitis [2]. Mutations that lead to CAPS are clustered inside or in the vicinity of the NOD domain (also referred as the NACHT domain), a module that is thought to be important in promoting the oligomerization of NLR proteins (Fig. 1). Initial experiments indicated that NLRP3 mutations in CAPS are gain-of-function mutations, in that over-expression of disease-associated mutants leads to increased secretion of IL-1 $\beta$ and macrophages from MWS patients secrete more IL-1 $\beta$ than healthy individuals $[71,72]$ (Fig. 1). These early studies uncovered the molecular basis on CAPS and paved the way to the treatment of CAPS with biologicals that target IL-1 $\beta$-induced signalling. However, the mechanism through which disease-associated mutations led to increased production of IL-1 $\beta$ is still poorly understood. One feature of the NOD domain that is thought to be important to induce the oligomerization of NLRP3 is its ability to bind to and hydrolyze ATP. This activity is required for CAPS-associated mutations to induce IL- $1 \beta$ secretion, suggesting that the gain-of function mutations in NLRP3 do not affect NLRP3 binding to ATP [73]. One possibility is that inhibitory signals that normally act on NLRP3 to repress its function fail to do so if the NOD domain of NLRP3 is mutated. In agreement with this possibility, cytosolic $\mathrm{K}^{+}$that normally prevents activation of the NLRP3-inflammasome fails to do so if cells harbour NLRP3-associated mutations [74,75]. One alternative possibility is that disease-associated NLRP3 mutations remove an inhibitory loop, making the NLRP3 variant constitutively active. In agreement with this possibility, stimulation with LPS that induces the up-regulation of NLRP3 is not sufficient to induce the activation of wild-type NLRP3, but is sufficient to induce caspase- 1 activation and IL-1 $\beta$ production in macrophages harbouring the NLRP3 mutations associated with CAPS $[74,75]$. Furthermore, production of IL- $1 \beta$ in monocytes from CAPS patients stimulated with PAMPs is maximal in the absence of ATP stimulation that is required instead to induce maximal production of IL-1 $\beta$ in monocytes from healthy individuals [53]. Recently, a mouse model of CAPS has been developed independently by two groups. Strober et al. generated a knock-in mouse harbouring the $\mathrm{R} 258 \mathrm{~W}$ mutation that corresponds to the R260W substitution found in patients with MWS and FCAS [75]. Hoffman et al. generated mouse strains carrying mutations (A350V that corresponds to the A352V variant found in MWS and L351P that corresponds to the L353P variant found in FCAS patients) downstream of a LoxP-flanked neomycin resistance cassette in a reverse orientation [74]. With this strategy the expression of the mutated NLRP3 protein is
Fig. 1. Right: nucleotide-binding domain and leucine-rich repeat containing family pyrin domain containing 3 (NLRP3) forms an inflammasome only in the presence of activating signals. Left: disease-associated mutations in NLRP3 are gain-of-function mutation located in the nucleotide oligomerization domain (NOD) domain that lead to a constitutive active protein. Cytosolic $\mathrm{K}^{+}$inhibits the formation of the NLRP3-inflammasome, but fails to do so in the presence of NLRP3 gain-of-function mutations.

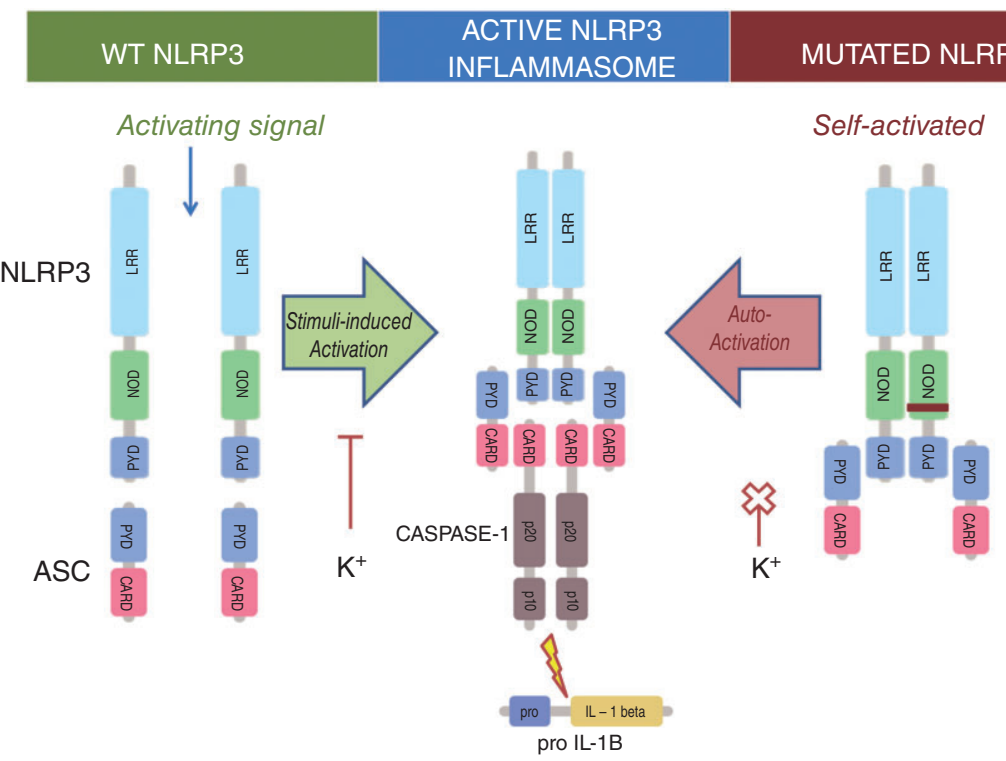


conditional to the expression of Cre-recombinase (Cre), and the authors were able to generate conditional knock-in mice expressing NLRP3 mutant in selected tissues by crossing the mice with mice expressing Cre under different promoters. Although the phenotypes of these mice show different severities of inflammation, all were characterized by the infiltration of neutrophils in the inflamed tissues [74,75]. Furthermore, the inflammatory response was due to the expression of NLRP3 mutants in the myeloid compartment and overproduction of IL-1 $\beta$ [74,75]. Importantly, Hoffman et al.'s work showed that disease manifestation is independent of the presence of $\mathrm{T}$ cells or $\mathrm{B}$ cells, thus providing experimental evidence that autoinflammatory syndromes are primarily disorders of the innate immune system [74]. It must be noted, however, that overproduction of IL- $1 \beta$ led to a T helper type 17 (Th17)-skewed phenotype. Interestingly, anti-IL-17 antibodies were found to ameliorate skin pathology, suggesting that certain disease manifestation may be exacerbated by Th17 cells [75]. This mouse model can help to address some unresolved questions. First, as this disease is not caused by an infection and the cells from these mice do not secrete IL-1 $\beta$ spontaneously, which are the stimuli that are triggering the production of IL- $1 \beta$ ? Secondly, as IL- $1 \beta$ is produced by different cells of myeloid origin, such as macrophages, dendritic cells and mast cells, which of these cells (and in which organ) are responsible for the pathological production of IL-1 $\beta$ ? Thirdly, why are several organs affected by the disease but others, such as the lung and the intestine, do not show any abnormality? Fourthly, why does the overproduction of IL-1 $\beta$ not predispose to autoimmune responses, when IL-1 $\beta$ is an effective adjuvant?

The important role of IL- $1 \beta$ in CAPS patients is underscored by the efficacy of biologicals that target IL- $1 \beta$ in the treatment of those patients. Recombinant IL-1Ra (anakinra), soluble IL-1 receptor (rilonacept) [76] and a human monoclonal antibody against IL-1 $\beta$ (canakinumab) [77] promote the rapid resolution of symptoms. Remarkably, biologicals that target IL-1 $\beta$ also proved to be effective in ameliorating the neurological symptoms in NOMID patients.

\section{Familial Mediterranean fever (FMF)}

FMF is the most prevalent hereditary autoinflammatory syndrome and is caused by mutations in MEFV (MEditerranean FeVer) which encodes for a 781 amino acid protein known as pyrin (or marenostrin) [3]. Human pyrin consists of four domains, an N-terminal pyrin domain (PYD), followed by two B-box zinc-finger and coiled-coil domains and a C-terminal B30.2 domain (also called SPRY). Most of the mutations responsible for FMF are located in the B30.2 domain. FMF is traditionally considered a recessive disorder based on the fact that both alleles are mutated in the majority of patients; however, there is evidence that disease can occur in patients harbouring a single mutated allele and up to $20 \%$ of patients that show clinical features of FMF (1-3-day-long sporadic attacks of fever and pain, involving unexplained peritonitis, pleuritis, synovitis, arthritis and erysipelas-like rashes) have no identifiable pyrin mutations [2]. FMF is relatively frequent in eastern Mediterranean populations, and the high rate of carriers harbouring missense mutations suggests that the variants confer a survival advantage [3].

Despite the well-established link between pyrin mutations and FMF, the physiological role of pyrin and how pyrin mutation promotes disease is still controversial, with opposing evidence suggesting that pyrin is a positive or negative regulator of caspase-1 activation. The interpretation that pyrin is a negative regulator of caspase- 1 fits with the fact that FMF is a recessive disorder. Initial findings based on the over-expression of pyrin in 293T cells showed that pyrin binds to ASC [78] and limits the activation of the NLRP3inflammasome [79]. Interestingly, data based on overexpression systems also suggested that the B30.2 domain can bind directly to and inhibit caspase- 1 activation, while FMFassociated mutations in the $\mathrm{B} 30 \cdot 2$ domain exhibit reduced binding and inhibition of caspase-1 $[79,80]$. In agreement with an anti-inflammatory role of pyrin, the downregulation of pyrin by siRNA in human acute monocytic leukaemia cell line-1 cells resulted in an increased production of IL-1 $\beta$ [80]. Furthermore, mice harbouring a truncated form of pyrin showed reduced response to LPS and were protected from LPS-induced lethality [81]. In contrast, Alnemri's group found that the over-expression of pyrin in $293 \mathrm{~T}$ cells that stably express ASC and caspase- 1 promote the activation of caspase-1 [82]. Moreover, Wewers' group found that the down-regulation of pyrin by siRNA in THP-1 cells or in primary monocytes led to reduced caspase- 1 activation and IL-1 $\beta$ [83]. Furthermore, there is evidence that pyrin is involved in the activation of caspase- 1 induced by LPS [83], Francisella [84], the retrovirus murine stem cell virus (MSCV) [82] and acts downstream of phosphataseinteracting protein 1 (PSTPIP1) [82], a protein that is mutated in pyogenic arthritis, pyoderma gangrenosum and acne syndrome (PAPA) syndrome, a related autoinflammatory disease. The two opposing models are depicted in Fig. 2. One possible explanation of the different results of those studies is that mouse pyrin differs from that of humans and lacks the B30-2 domain, making it difficult to study the role of pyrin in mouse models. Recently, in an attempt to resolve these controversies, the Kastner group generated a mouse harbouring a chimeric protein of the mouse pyrin fused to the human B30.2 domain (pyrin-mB30.2) [85] and pyrin knock-out mice. Although the expression of the fusion protein containing wild-type B30.2 domain was lethal, somewhat limiting the interpretation of the results, the authors were able to generate mice in which the $\mathrm{B} 30.2$ domain harboured the mis-sense mutations found in FMF and reported that homozygous mice develop a spontaneous activation of the inflammasome and a systemic inflammatory response [85]. In contrast, pyrin knock-out mice do not 
Fig. 2. Two different models have been proposed to explain how mutations in PYRIN lead to familial Mediterranean fever (FMF). In one model pyrin is a positive regulator and promote the activation of caspase- 1 in response to specific stimuli. Dominant gain-of-function mutations lead to a constitutive active protein, similarly to what happen for the gain-offunction mutation in nucleotide-binding domain and leucine-rich repeat containing family pyrin domain containing 3 (NLRP3). Alternatively, pyrin is a negative regulator of caspase-1. According to this model, recessive loss-of-function mutations fail to control the activation of caspase-1 leading to the inflammatory response observed in FMF.

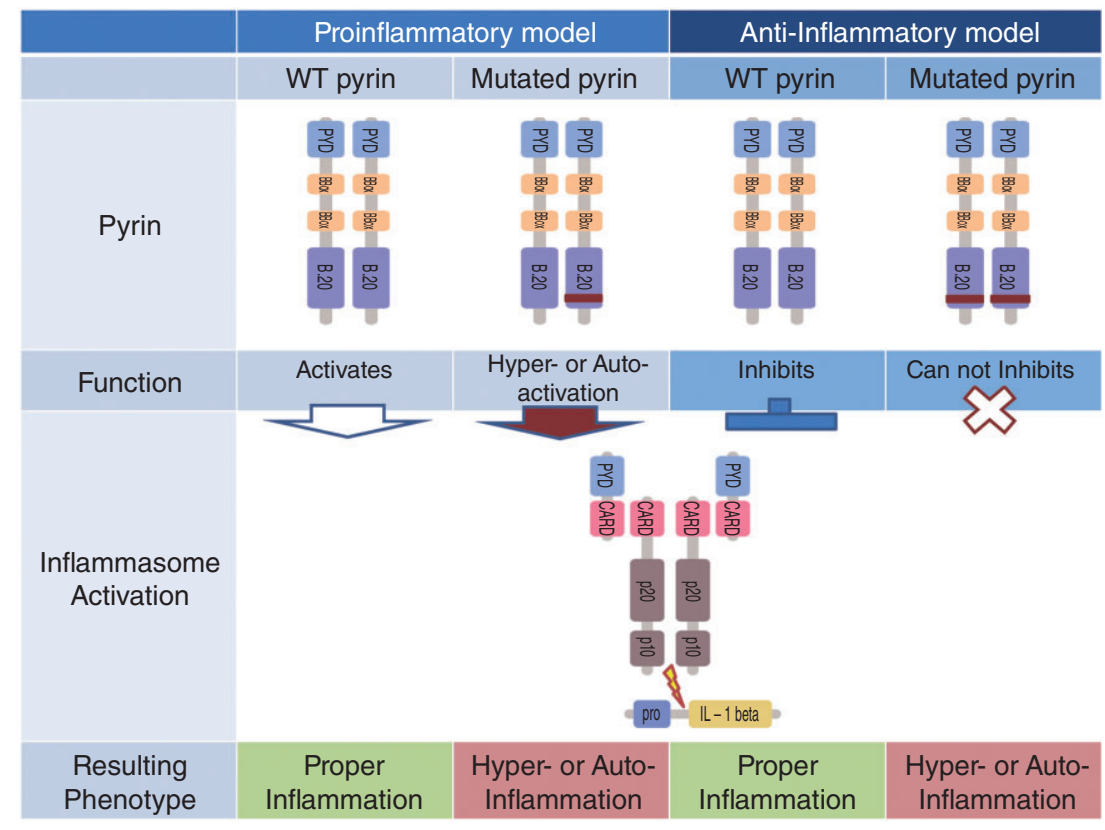

show any obvert phenotype, indicating that the functional role of pyrin-mB30.2 and pyrin is different and suggest that pyrin-mB30.2 is a valuable model of FMF. Consistent with FMF caused by genetic lesions of the innate immune system, pyrin is expressed mainly in innate immune cells such as neutrophils, monocytes and dendritic cells, but not in lymphocytes. In an elegant set of experiments, the Kastner group showed that bone-marrow transplantation of donor pyrin-mB30.2 in wild-type recipients induces the development of an inflammatory phenotype that recapitulates the disease manifestation seen in unmanipulated pyrin-mB30.2 knock-in mice [85]. The authors also performed an experiment with bone-marrow transplantation of wild-type haematopoietic cells into recipient pyrin-mB30.2 knock-in mice. As the knock-in mice develop severe symptoms early in life, the authors were forced to adopt a suboptimal protocol of bone-marrow transplantation, but a careful analysis of the efficiency of chimerism in transplanted mice indicate a strong correlation between the efficiency of bone-marrow transplantation and the amelioration of the disease [85]. Furthermore, the authors performed experiments to test the role of adaptive immunity in FMF. To this end, they generated pyrin-mB30.2 knock-in mice in a Rag1-deficient background, which are deficient in $\mathrm{T}$ lymphocyte and $\mathrm{B}$ lymphocytes, and showed that these mice develop an autoinflammatory syndrome similar to the one in pyrin-mB30.2 knock-in mice. Importantly, by generating pyrin-mB30.2 knock-in mice in a background deficient in inflammasome components, the authors proved that the disease was dependent on caspase-1, ASC and IL-1 signalling but was independent of NLRP3, NLRC4 and AIM2 [85]. As mentioned previously, the disease developed only in homozygous mice, which is consistent with a recessive mode of inheritance, and the authors suggest that pyrin mutations are gain-offunction mutations with a dosage effect in inducing disease. A main question that remains to be addressed is whether pyrin is physiologically an adaptor or forms an inflammasome using the $\mathrm{B} 30 \cdot 2$ domain to sense microbes.

FMF is treated routinely with colchicine, a drug that is known to target microtubules [86]. However, the mechanism of action of colchicine in FMF is not clear, and may be due to either the inhibition of the inflammasome or to the inhibition of the migration of inflammatory cells in inflamed tissues. Nevertheless, some patients are not sensitive, or intolerant, to colchicine. In those patients biologicals that target IL-1 $\beta$ have been shown to be effective [87].

\section{Conclusions and future perspectives}

Understanding that gain-of-function mutations in NLRP3, along with the discovery of the role of NLRP3 in activating caspase- 1 and IL-1 $\beta$ production, have led to the use of biologicals that target IL-1 $\beta$ signalling to treat disease. Other hereditary syndromes [such as FMF, PAPA syndrome and hyperimmunoglobulinaemia D with periodic fever syndrome (HIDS)] may be due to increased activation of inflammasomes and elevated production of IL-1 $\beta$. Identification of genes involved in other hereditary autoinflammatory syndromes may lead to a better understanding of the inflammasome and new targets to treat these inflammatory disorders. One of the challenges for the future will be assessing the role of inflammasomes and IL- $1 \beta$ in other hereditary syndromes in which the gene responsible for the disease has not yet been identified, as well as in complex and polygenic conditions characterized by an exaggerated activation of the 
innate immune system, such as gout, pseudogout and type 2 diabetes mellitus.

\section{Acknowledgements}

The authors are grateful to Gabriel Nunez for critical review of the manuscript. L.F. is supported by a Career Development Award from Crohn's and Colitis Foundation of America (CCFA). We apologize to those authors whose work could not be cited due to space limitations.

\section{Disclosure}

The authors declare that no conflict of interest exists.

\section{References}

1 Masters SL, Simon A, Aksentijevich I, Kastner DL. Horror autoinflammaticus: the molecular pathophysiology of autoinflammatory disease $\left(^{*}\right)$. Annu Rev Immunol 2009; 27:621-68.

2 Hoffman HM, Simon A. Recurrent febrile syndromes: what a rheumatologist needs to know. Nat Rev Rheumatol 2009; 5:249-56.

3 Kastner DL, Aksentijevich I, Goldbach-Mansky R. Autoinflammatory disease reloaded: a clinical perspective. Cell 2010; 140:784-90.

4 Goldbach-Mansky R. Immunology in clinic review series; focus on autoinflammatory diseases: update on monogenic autoinflammatory diseases: the role of interleukin (IL)-1 and an emerging role for cytokines beyond IL-1. Clin Exp Immun 2012; 167:391-404.

5 Dinarello CA. Biologic basis for interleukin-1 in disease. Blood 1996; 87:2095-147.

6 Bochner BS, Luscinskas FW, Gimbrone MA et al. Adhesion of human basophils, eosinophils, and neutrophils to interleukin 1-activated human vascular endothelial cells: contributions of endothelial cell adhesion molecules. J Exp Med 1991; 173:1553-7.

7 Russo HM, Wickenheiser KJ, Luo W et al. P-selectin glycoprotein ligand-1 regulates adhesive properties of the endothelium and leukocyte trafficking into adipose tissue. Circ Res 2010; 107:388-97.

8 Dinarello CA. A clinical perspective of IL-1beta as the gatekeeper of inflammation. Eur J Immunol 2011; 41:1203-17.

9 van de Veerdonk FL, Netea MG, Dinarello CA, Joosten LA. Inflammasome activation and IL-1beta and IL-18 processing during infection. Trends Immunol 2011; 32:110-16.

10 Franchi L, McDonald C, Kanneganti TD, Amer A, Nunez G. Nucleotide-binding oligomerization domain-like receptors: intracellular pattern recognition molecules for pathogen detection and host defense. J Immunol 2006; 177:3507-13.

11 Franchi L, Park JH, Shaw MH et al. Intracellular NOD-like receptors in innate immunity, infection and disease. Cell Microbiol 2008; 10:1-8.

12 Embry CA, Franchi L, Nunez G, Mitchell TC. Mechanism of impaired NLRP3 inflammasome priming by monophosphoryl lipid A. Sci Signal 2011; 4:ra28.

13 Marina-Garcia N, Franchi L, Kim YG et al. Clathrin- and dynamindependent endocytic pathway regulates muramyl dipeptide internalization and NOD2 activation. J Immunol 2009; 182:4321-7.

14 Samavati L, Rastogi R, Du W, Huttemann M, Fite A, Franchi L. STAT3 tyrosine phosphorylation is critical for interleukin 1 beta and interleukin-6 production in response to lipopolysaccharide and live bacteria. Mol Immunol 2009; 46:1867-77.
15 Franchi L, Eigenbrod T, Munoz-Planillo R, Nunez G. The inflammasome: a caspase-1-activation platform that regulates immune responses and disease pathogenesis. Nat Immunol 2009; 10:241-7.

16 Martinon F, Tschopp J. Inflammatory caspases and inflammasomes: master switches of inflammation. Cell Death Differ 2007; 14:10-22.

17 Qu Y, Ramachandra L, Mohr S et al. P2X7 receptor-stimulated secretion of MHC class II-containing exosomes requires the ASC/ NLRP3 inflammasome but is independent of caspase-1. J Immunol 2009; 182:5052-62.

18 MacKenzie A, Wilson HL, Kiss-Toth E, Dower SK, North RA, Surprenant A. Rapid secretion of interleukin-1beta by microvesicle shedding. Immunity 2001; 15:825-35.

19 Andrei C, Dazzi C, Lotti L, Torrisi MR, Chimini G, Rubartelli A. The secretory route of the leaderless protein interleukin lbeta involves exocytosis of endolysosome-related vesicles. Mol Biol Cell 1999; 10:1463-75.

20 Brough D, Rothwell NJ. Caspase-1-dependent processing of prointerleukin-1beta is cytosolic and precedes cell death. J Cell Sci 2007; 120:772-81.

21 Horai R, Saijo S, Tanioka H et al. Development of chronic inflammatory arthropathy resembling rheumatoid arthritis in interleukin 1 receptor antagonist-deficient mice. J Exp Med 2000; 191:313-20.

22 Nicklin MJ, Hughes DE, Barton JL, Ure JM, Duff GW. Arterial inflammation in mice lacking the interleukin 1 receptor antagonist gene. J Exp Med 2000; 191:303-12.

23 Aksentijevich I, Masters SL, Ferguson PJ et al. An autoinflammatory disease with deficiency of the interleukin-1-receptor antagonist. N Engl J Med 2009; 360:2426-37.

24 Reddy VS, Harskamp RE, van Ginkel MW et al. Interleukin-18 stimulates fibronectin expression in primary human cardiac fibroblasts via PI3K-Akt-dependent NF-kappaB activation. J Cell Physiol 2008; 215:697-707.

25 Bauernfeind F, Ablasser A, Bartok E et al. Inflammasomes: current understanding and open questions. Cell Mol Life Sci 2011; 68:76583.

26 Martinon F, Burns K, Tschopp J. The inflammasome: a molecular platform triggering activation of inflammatory caspases and processing of proIL-beta. Mol Cell 2002; 10:417-26.

27 Mankan AK, Kubarenko A, Hornung V. Immunology in the clinic review series; focus on autoinflammatory diseases: inflammasomes: mechanisms of activation. Clin Exp Immun 2012; 167:369-81.

28 Faustin B, Lartigue L, Bruey JM et al. Reconstituted NALP1 inflammasome reveals two-step mechanism of caspase-1 activation. Mol Cell 2007; 25:713-24.

29 Franchi L, Amer A, Body-Malapel M et al. Cytosolic flagellin requires Ipaf for activation of caspase-1 and interleukin 1beta in salmonella-infected macrophages. Nat Immunol 2006; 7:576-82.

30 Miao EA, Alpuche-Aranda CM, Dors M et al. Cytoplasmic flagellin activates caspase-1 and secretion of interleukin 1beta via Ipaf. Nat Immunol 2006; 7:569-75.

31 Franchi L, Stoolman J, Kanneganti TD, Verma A, Ramphal R, Nunez G. Critical role for Ipaf in Pseudomonas aeruginosa-induced caspase-1 activation. Eur J Immunol 2007; 37:3030-9.

32 Amer A, Franchi L, Kanneganti TD et al. Regulation of Legionella phagosome maturation and infection through flagellin and host Ipaf. J Biol Chem 2006; 281:35217-23.

33 Franchi L, Warner N, Viani K, Nunez G. Function of Nod-like receptors in microbial recognition and host defense. Immunol Rev 2009; 227:106-28. 
34 Kofoed EM, Vance RE. Innate immune recognition of bacterial ligands by NAIPs determines inflammasome specificity. Nature 2011; 477:592-5.

35 Suzuki T, Franchi L, Toma C et al. Differential regulation of caspase- 1 activation, pyroptosis, and autophagy via Ipaf and ASC in Shigella-infected macrophages. PLoS Pathog 2007; 3:e111.

36 Miao EA, Mao DP, Yudkovsky N et al. Innate immune detection of the type III secretion apparatus through the NLRC4 inflammasome. Proc Natl Acad Sci USA 2010; 107:3076-80.

37 Alnemri ES. Sensing cytoplasmic danger signals by the inflammasome. J Clin Immunol 2010; 30:512-19.

38 Hornung V, Latz E. Intracellular DNA recognition. Nat Rev Immunol 2010; 10:123-30.

39 Franchi L, Kanneganti TD, Dubyak GR, Nunez G. Differential requirement of $\mathrm{P} 2 \mathrm{X} 7$ receptor and intracellular $\mathrm{K}+$ for caspase-1 activation induced by intracellular and extracellular bacteria. J Biol Chem 2007; 282:18810-18.

$40 \mathrm{Kim}$ S, Bauernfeind F, Ablasser A et al. Listeria monocytogenes is sensed by the NLRP3 and AIM2 Inflammasome. Eur J Immunol 2010; 40:1545-51.

41 Mariathasan S, Weiss DS, Newton K et al. Cryopyrin activates the inflammasome in response to toxins and ATP. Nature 2006; 440:228-32.

42 Rathinam VA, Jiang Z, Waggoner SN et al. The AIM2 inflammasome is essential for host defense against cytosolic bacteria and DNA viruses. Nat Immunol 2010; 11:395-402.

43 Sauer JD, Witte CE, Zemansky J, Hanson B, Lauer P, Portnoy DA. Listeria monocytogenes triggers AIM2-mediated pyroptosis upon infrequent bacteriolysis in the macrophage cytosol. Cell Host Microbe 2010; 7:412-19.

44 Tsuchiya K, Hara H, Kawamura I et al. Involvement of absent in melanoma 2 in inflammasome activation in macrophages infected with Listeria monocytogenes. J Immunol 2010; 185:1186-95.

45 Mayer-Barber KD, Barber DL, Shenderov K et al. Caspase-1 independent IL-1beta production is critical for host resistance to mycobacterium tuberculosis and does not require TLR signaling in vivo. J Immunol 2010; 184:3326-30.

46 Dinarello CA. Interleukin-1 in the pathogenesis and treatment of inflammatory diseases. Blood 2011; 117:3720-32.

47 Cassel SL, Sutterwala FS. Sterile inflammatory responses mediated by the NLRP3 inflammasome. Eur J Immunol 2010; 40:607-11.

48 Franchi L, Munoz-Planillo R, Reimer T, Eigenbrod T, Nunez G. Inflammasomes as microbial sensors. Eur J Immunol 2010; 40:611-15.

49 Kahlenberg JM, Lundberg KC, Kertesy SB, Qu Y, Dubyak GR. Potentiation of caspase- 1 activation by the $\mathrm{P} 2 \mathrm{X} 7$ receptor is dependent on TLR signals and requires NF-kappaB-driven protein synthesis. J Immunol 2005; 175:7611-22.

50 Bauernfeind FG, Horvath G, Stutz A et al. Cutting edge: NF-kappaB activating pattern recognition and cytokine receptors license NLRP3 inflammasome activation by regulating NLRP3 expression. J Immunol 2009; 183:787-91.

51 Franchi L, Eigenbrod T, Nunez G. Cutting edge: TNF-\{alpha\} mediates sensitization to ATP and silica via the NLRP3 inflammasome in the absence of microbial stimulation. J Immunol 2009; 183:792-6.

52 Netea MG, Nold-Petry CA, Nold MF et al. Differential requirement for the activation of the inflammasome for processing and release of IL-1beta in monocytes and macrophages. Blood 2009; 113:232435.
53 Piccini A, Carta S, Tassi S, Lasiglie D, Fossati G, Rubartelli A. ATP is released by monocytes stimulated with pathogen-sensing receptor ligands and induces IL-1beta and IL-18 secretion in an autocrine way. Proc Natl Acad Sci USA 2008; 105:8067-72.

54 Harder J, Franchi L, Munoz-Planillo R, Park JH, Reimer T, Nunez G. Activation of the Nlrp3 inflammasome by Streptococcus pyogenes requires streptolysin $\mathrm{O}$ and NF-kappaB activation but proceeds independently of TLR signaling and P2X7 receptor. J Immunol 2009; 183:5823-9.

55 Munoz-Planillo R, Franchi L, Miller LS, Nunez G. A critical role for hemolysins and bacterial lipoproteins in Staphylococcus aureusinduced activation of the Nlrp3 inflammasome. J Immunol 2009; 183:3942-8.

56 Kanneganti TD, Ozoren N, Body-Malapel M et al. Bacterial RNA and small antiviral compounds activate caspase-1 through cryopyrin/Nalp3. Nature 2006; 440:233-6.

57 Rathinam VA, Fitzgerald KA. Inflammasomes and anti-viral immunity. J Clin Immunol 2010; 30:632-7.

58 Joly S, Sutterwala FS. Fungal pathogen recognition by the NLRP3 inflammasome. Virulence 2010; 1:276-80.

59 Ferrari D, Pizzirani C, Adinolfi E et al. The P2X7 receptor: a key player in IL-1 processing and release. J Immunol 2006; 176:387783.

60 Martinon F, Petrilli V, Mayor A, Tardivel A, Tschopp J. Goutassociated uric acid crystals activate the NALP3 inflammasome. Nature 2006; 440:237-41.

61 Duewell P, Kono H, Rayner KJ et al. NLRP3 inflammasomes are required for atherogenesis and activated by cholesterol crystals. Nature 2010; 464:1357-61.

62 Masters SL, Dunne A, Subramanian SL et al. Activation of the NLRP3 inflammasome by islet amyloid polypeptide provides a mechanism for enhanced IL-1beta in type 2 diabetes. Nat Immunol 2010; 11:897-904.

63 Hornung V, Bauernfeind F, Halle A et al. Silica crystals and aluminum salts activate the NALP3 inflammasome through phagosomal destabilization. Nat Immunol 2008; 9:847-56.

64 Franchi L, Chen G, Marina-Garcia N et al. Calcium-independent phospholipase A2beta is dispensable for inflammasome activation and its inhibition by bromoenol lactone. J Innate Immun 2009; 1:607-17.

65 Zhou R, Tardivel A, Thorens B, Choi I, Tschopp J. Thioredoxininteracting protein links oxidative stress to inflammasome activation. Nat Immunol 2010; 11:136-40.

66 Meissner F, Molawi K, Zychlinsky A. Superoxide dismutase 1 regulates caspase-1 and endotoxic shock. Nat Immunol 2008; 9:866-72.

67 Bauernfeind F, Bartok E, Rieger A, Franchi L, Nunez G, Hornung V. Cutting edge: reactive oxygen species inhibitors block priming, but not activation, of the NLRP3 inflammasome. J Immunol 2011; 187:613-17.

68 van de Veerdonk FL, Smeekens SP, Joosten LA et al. Reactive oxygen species-independent activation of the IL-1beta inflammasome in cells from patients with chronic granulomatous disease. Proc Natl Acad Sci USA 2010; 107:3030-3.

69 Feldmann J, Prieur AM, Quartier P et al. Chronic infantile neurological cutaneous and articular syndrome is caused by mutations in CIAS1, a gene highly expressed in polymorphonuclear cells and chondrocytes. Am J Hum Genet 2002; 71:198-203.

70 Hoffman HM, Mueller JL, Broide DH, Wanderer AA, Kolodner RD. Mutation of a new gene encoding a putative pyrin-like protein 
causes familial cold autoinflammatory syndrome and MuckleWells syndrome. Nat Genet 2001; 29:301-5.

71 Agostini L, Martinon F, Burns K, McDermott MF, Hawkins PN, Tschopp J. NALP3 forms an IL-1beta-processing inflammasome with increased activity in Muckle-Wells autoinflammatory disorder. Immunity 2004; 20:319-25.

72 Dowds TA, Masumoto J, Zhu L, Inohara N, Nunez G. Cryopyrininduced interleukin lbeta secretion in monocytic cells: enhanced activity of disease-associated mutants and requirement for ASC. J Biol Chem 2004; 279:21924-8.

73 Duncan JA, Bergstralh DT, Wang Y et al. Cryopyrin/NALP3 binds ATP/dATP, is an ATPase, and requires ATP binding to mediate inflammatory signaling. Proc Natl Acad Sci USA 2007; 104:8041-6.

74 Brydges SD, Mueller JL, McGeough MD et al. Inflammasomemediated disease animal models reveal roles for innate but not adaptive immunity. Immunity 2009; 30:875-87.

75 Meng G, Zhang F, Fuss I, Kitani A, Strober W. A mutation in the Nlrp3 gene causing inflammasome hyperactivation potentiates Th17 cell-dominant immune responses. Immunity 2009; 30:86074.

76 Hoffman HM, Throne ML, Amar NJ et al. Efficacy and safety of rilonacept (interleukin-1 Trap) in patients with cryopyrinassociated periodic syndromes: results from two sequential placebo-controlled studies. Arthritis Rheum 2008; 58:2443-52.

77 Lachmann HJ, Kone-Paut I, Kuemmerle-Deschner JB et al. Use of canakinumab in the cryopyrin-associated periodic syndrome. N Engl J Med 2009; 360:2416-25.

78 Dowds TA, Masumoto J, Chen FF, Ogura Y, Inohara N, Nunez G. Regulation of cryopyrin/Pypaf1 signaling by pyrin, the familial Mediterranean fever gene product. Biochem Biophys Res Commun 2003; 302:575-80.

79 Papin S, Cuenin S, Agostini L et al. The SPRY domain of pyrin, mutated in familial Mediterranean fever patients, interacts with inflammasome components and inhibits proIL-1beta processing. Cell Death Differ 2007; 14:1457-66.

80 Chae JJ, Wood G, Masters SL et al. The B30.2 domain of pyrin, the familial Mediterranean fever protein, interacts directly with caspase-1 to modulate IL-1beta production. Proc Natl Acad Sci USA 2006; 103:9982-7.

81 Chae JJ, Komarow HD, Cheng J et al. Targeted disruption of pyrin, the FMF protein, causes heightened sensitivity to endotoxin and a defect in macrophage apoptosis. Mol Cell 2003; 11:591604.

$82 \mathrm{Yu}$ JW, Fernandes-Alnemri T, Datta P et al. Pyrin activates the ASC pyroptosome in response to engagement by autoinflammatory PSTPIP1 mutants. Mol Cell 2007; 28:214-27.

83 Seshadri S, Duncan MD, Hart JM, Gavrilin MA, Wewers MD. Pyrin levels in human monocytes and monocyte-derived macrophages regulate IL-1beta processing and release. J Immunol 2007; 179:1274-81.

84 Gavrilin MA, Mitra S, Seshadri S et al. Pyrin critical to macrophage IL-1 $\{$ beta\} response to Francisella challenge. J Immunol 2009; 182:7982-9.

85 Chae JJ, Cho YH, Lee GS et al. Gain-of-function pyrin mutations induce NLRP3 protein-independent interleukin-1beta activation and severe autoinflammation in mice. Immunity 2011; 34:755-68.

86 Dinarello CA, Wolff SM, Goldfinger SE, Dale DC, Alling DW. Colchicine therapy for familial Mediterranean fever. A doubleblind trial. N Engl J Med 1974; 291:934-7.

87 Hennig S, Bayegan K, Uffmann M, Thalhammer F, Winkler S. Pneumonia in a patient with familial Mediterranean fever successfully treated with anakinra-case report and review. Rheumatol Int 2010; doi: 10.1007/s00296-010-1429-y. 